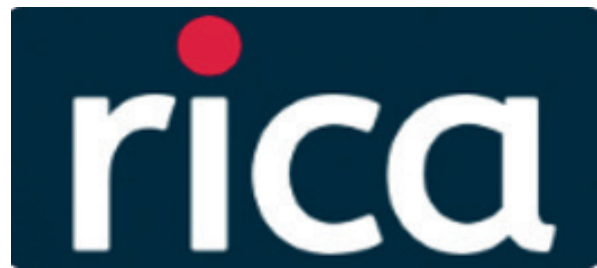

RICA - v. 5 n. 9, 2021

Revista Interdisciplinar de Ciência Aplicada

ISSN: 2525-3824

\title{
Professora Vania Elisabete Schneider e a alquimia de transformar "lixo" em ciência
}

\author{
Gladis Franck da Cunha (gladisfranck@gmail.com) \\ Nilva Lúcia Rech Stedile (nIrstedi@ucs.br) \\ Valquíria Villas-Boas (vvbgmiss@ucs.br) \\ Matheus Poletto (mpolett1@ucs.br) \\ Fernanda Marcon Angheben (fmarcon1@ucs.br)
}

Universidade de Caxias do Sul.

DOI: $10.18226 / 25253824 . v 5 . n 9.01$

Resumo: Este artigo homenageia uma professora amiga e pesquisadora. Ou seria uma pesquisadora, amiga e professora? Essas dúvidas se evidenciam ao longo do artigo, pois o leitor verá como é difícil separar essas três dimensões. Nossa "alquimista" tem como uma de suas características compartilhar com os acadêmicos e colegas dos vários cursos de graduação e pós-graduação em que leciona todas as suas descobertas, entusiasmo e habilidades de pesquisa de forma intensa e amorosa. Apesar de seu extenso e impressionante currículo acadêmico e profissional, a professora Vania se destaca pela generosidade acadêmica e por "abraçar" as pessoas, colocando-as como iguais. Destacam-se, ainda, suas saídas à campo, sempre repletas de motivação, alegria e seriedade, seu labor incansável por equipar os laboratórios de pesquisa e/ou ensino em que atua e sua produção científica, fruto de muitos projetos de pesquisa aprovados por agências de fomento. Ela escreve e publica muitos artigos e tem organizado muitos eventos científicos importantes. Impressionante como o mar, Vania é aquela educadora que forma em qualquer espaço e a bióloga apaixonada que insiste em querer salvar o planeta e nos impõe um amor e uma responsabilidade pela qualidade ambiental e de vida.

Palavras-chaves: Vania Elisabete Schneider. Professora. Pesquisadora. Amiga.

Abstract: This article pays homage to a teacher, friend and researcher or is it a researcher, friend and teacher? These doubts are evident throughout the article, as the reader will see how difficult it is to separate these three dimensions. Our "alchemist" has as one of her characteristics to share with the academics and colleagues of the various courses in which she teaches all her discoveries, enthusiasm and research skills in an intense and loving way. Despite her extensive and impressive academic and professional curriculum, Professor Vania stands out for her academic generosity and for "embracing" people by placing them as equals. Also noteworthy are her field classes, always full of motivation, joy and seriousness, her tireless work for equipping the research and / or teaching laboratories in which she operates and her scientific production in which she wins many projects from development agencies, writes and publishes many articles and has organized many important scientific events. Impressive as the sea, Vania is the educator who trains in any space, she is the passionate biologist who insists on wanting to save the planet and imposes on us a love and a responsibility for environmental quality is due.

Keywords: Vania Elisabete Schneider. Professor. Researcher. Friend.

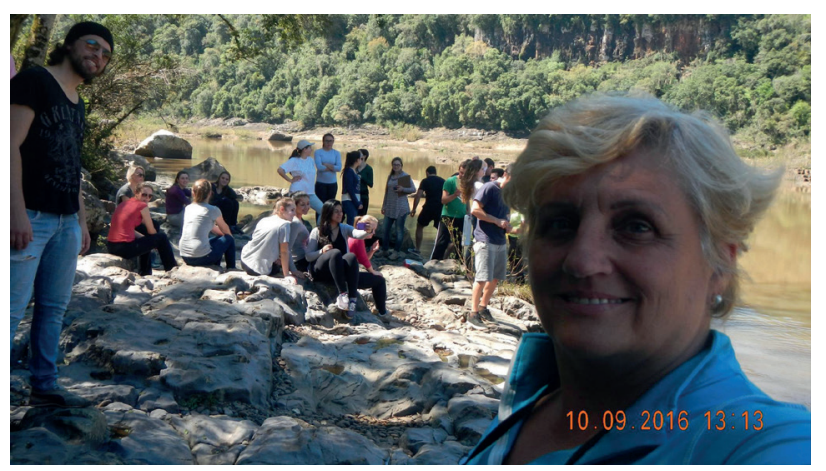

Figura 1: Vania, em primeiro plano, registra os alunos em uma aula de campo em 2016 (foto obtida do acervo de seu perfil no Facebook).

\section{INTRODUÇÃO}

Para começo de conversa, o uso do substantivo "lixo" é apenas uma licença poética bem-humorada, porque sabemos que o termo correto seria resíduo sólido, e uma provocação, porque, ao ler o título, nossa homenageada vai reclamar, mas o corpo do artigo vai compensar o breve desconforto inicial.

Este artigo retoma as homenagens aos professores que marcam as vidas acadêmicas de seus estudantes e entram para a galeria de pessoas inesquecíveis. A ideia, aqui, não é a abordagem científica, mas pessoal, explorando os aspectos emocionais da convivência com pessoas tão inspiradoras que são consideradas
"Modelo de Professor(a)". Em especial, esta homenagem foi pensada como uma surpresa, por isso as imagens que ilustram o artigo foram obtidas do arquivo de fotos públicas compartilhadas pela nossa homenageada em seu perfil do Facebook ou arquivos pessoais dos autores, pois não foram tiradas fotografias especiais para esta publicação.

Nossa homenageada desta edição é a professora, bióloga e ecologista Vania Elisabete Schneider, um modelo de professora que entrelaça a pesquisa e o ensino desde os seus primeiros passos na carreira docente na Universidade de Caxias do Sul, pois, para ela, uma coisa não existe sem a outra. Assim, todas as suas descobertas e habilidades de pesquisa são compartilhadas com os acadêmicos dos vários cursos em que leciona. Todas as suas disciplinas estão recheadas de atividades práticas de pesquisa, que tanto contribuem para a formação profissional dos estudantes quanto têm fornecido dados para algumas de suas pesquisas e publicações. Ou seja, suas práticas de campo e de laboratório são sempre "de verdade" e os alunos devem se portar como pesquisadores, com toda a seriedade, a ética e a responsabilidade que as tarefas de observação, coleta e análise de dados exigem.

Além disso, Vania é um exemplo de generosidade acadêmica e sempre procura oportunidades de bolsas para os estudantes que se destacam em suas disciplinas e mostram um vivo interesse pela Ecologia e Educação Ambiental. Como qualquer ser humano, ela também tem seus defeitos, mas não são eles que deixam as prin 


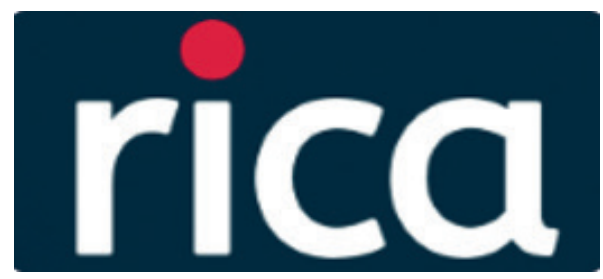

\author{
RICA - v. 5 n. 9, 2021 \\ Revista Interdisciplinar de Ciência Aplicada \\ ISSN: 2525-3824
}

cipais lembranças em nossos corações e mentes, pois a sensação que fica para quem a conhece é a de uma pessoa extraordinária.

\section{Um breve resumo de uma complexa trajetória}

O currículo da Professora Vania Schneider na plataforma Lattes [1] apresenta um breve resumo da sua trajetória profissional desde a formação na Graduação até os aspectos mais relevantes de atuação, selecionados por ela mesma. Assim, decidimos transcrevê-lo abaixo como forma de apresentação. Mantivemos o texto original, mas alteramos o formato de apresentação, separando seu conteúdo em quatro parágrafos a fim de facilitar a leitura e permitir que leitor tome fôlego entre um parágrafo e outro:

Graduada em Licenciatura Plena e Bacharelado em Biologia pela Universidade de Caxias do Sul (1989); Especialista em Metodologia da Pesquisa e do Ensino Superior - Área de Concentração: Educação Ambiental; Mestre em Engenharia Civil - Área de Concentração - Recursos Hídricos e Saneamento pela Universidade Estadual de Campinas (1994); Doutora em Engenharia de Recursos Hídricos e Saneamento Ambiental pelo Instituto de Pesquisas Hidráulicas (IPH) da Universidade Federal do Rio Grande do Sul (2005).

Professora Titular e Diretora do Instituto de Saneamento Ambiental da Universidade de Caxias do Sul; Revisora dos periódicos: Revista Panamericana de Salud Pública, Revista Engenharia Sanitária e Ambiental, Revista Biociências; Parecerista ad hoc da Universidade Severino Sombra; Consultor ad hoc da Fundação de Apoio ao Desenvolvimento do Ensino, Ciência e Tecnologia do MS.

Integrante dos conselhos municipais de defesa do meio ambiente de Caxias do Sul e Bento Gonçalves (suplente); Membro do Comitê de Gerenciamento da Bacia Hidrográfica do Rio Taquari Antas. Responsável técnica do Instituto Porto Alegre Ambiental; Coordenadora do Congresso Internacional de Tecnologias Ambientais e Diretora da Fiema Brasil - Feira Internacional de Tecnologia para o Meio Ambiente. Membro da diretoria no Conselho consultivo da Associação Brasileira de Engenharia Sanitária e Ambiental - RS.

Tem experiência nas áreas de Biologia, Engenharia Ambiental, Enfermagem, Engenharia Civil e Arquitetura atuando principalmente nos seguintes temas: gerenciamento de resíduos sólidos - Resíduos Sólidos Urbanos, Resíduos de Serviços de Saúde, Resíduos da Construção Civil, Resíduos de madeira e Resíduos no meio Rural; Gestão de Recursos Hídricos e Monitoramento da Qualidade da Água; Gestão Ambiental; Saneamento Ambiental; Formação de Professores para o ensino de ciências e Biologia. [1]

Cada um dos parágrafos anteriores já daria um belo currículo, mas a soma de todos é impressionante. Apesar de "intenso" e extenso, esse resumo disponível no Lattes não reflete a totalidade da vida da Professora Vania, pois uma breve consulta nas fotos do seu perfil no Facebook revela uma mescla de cenas de trabalho com a vida familiar e muitas viagens pelos "quatro cantos do mundo". Por esse motivo é importante esmiuçar um pouco mais dessa trajetória tão rica em depoimentos, nos quais cada um dos coautores vai explorar alguns aspectos da história de vida da Prof. . . Vania, fazendo um recorte pessoal muito mais emocional que analítico.

\section{OS ANOS NOVENTA E OS PRIMEIROS PASSOS COMO DOCENTE DA UCS}

Iniciamos nossa carreira como docentes do Ensino Superior no dia $1^{\circ}$ de agosto de 1990 na Faculdade de Educação, Ciências e Letras (Feclervi), que era mantida pela Fundação Educacional da Região dos Vinhedos (Fervi) no município de Bento Gonçalves. O curso era uma Licenciatura Curta em Ciências e Matemática. Como um dos professores de disciplinas biológicas havia se aposentado, num primeiro momento, por eu já ter concluído o mestrado, o então diretor da Feclervi, Prof. José Carlos Köche, me chamou para assumir as três disciplinas daquele professor, mas, felizmente, como eu ainda morava em Porto Alegre, só poderia assumir duas e escolhi as da área morfológica (histologia e embriologia) e de botânica, pois a outra disciplina era de Elementos de Geologia, na qual minha formação foi fraca.

Graças à minha indisponibilidade de horários, a Vania foi contratada para assumir a disciplina de Geologia. Na verdade, o currículo do curso favorecia essa área, pois, embora as demais disciplinas fossem mais gerais e deveriam abarcar muitos conteúdos da Biologia, a Geologia estava dividida em duas disciplinas, chamadas de Elementos de Geologia Dinâmica Interna e Elementos de Geologia Dinâmica Externa. Assim, começamos a trabalhar no mesmo dia, uma sexta-feira à noite, que não costuma ser o preferido dos professores que atuam em cursos noturnos, então seguimos nos encontrando todas as sextas durante os três primeiros anos, antes da Vania iniciar seu mestrado na Unicamp (SP). Desse modo, nos tornamos parceiras de "aventuras" e eu pude acompanhar os primeiros passos do seu extenso currículo na educação superior.

Nas conversas fui conhecendo uma mulher guerreira, que cursou Biologia em uma universidade que, apesar de ser comunitária, não é pública e todos os seus cursos são pagos. Além da disponibilidade de tempo e dedicação aos estudos, durante a graduação ela tinha dois filhos pequenos e, para sustentar todos esses custos, por muito tempo fez e vendeu tortas. Quando a conheci, ela já estava divorciada e ainda precisava fazer tortas para complementar a renda. Só essas histórias já dariam um livro, mas o que nos move neste artigo é destacar o fato de a Vania ser um "Modelo de Professora".

Em relação à nossa atuação na Feclervi, nos primeiros anos fizemos algumas revoluções no curso de Licenciatura em 


\section{RICA - v. 5 n. 9, 2021 \\ Revista Interdisciplinar de Ciência Aplicada \\ ISSN: 2525-3824}

Ciências e Matemática, ativando os laboratórios de Biologia e de Geologia para a realização das aulas práticas nessas áreas, pois somente os professores de Física e Química costumavam fazer aulas práticas com os licenciandos. Enquanto eu ativava o laboratório de Biologia, botando em uso os microscópios, comprando lâminas para aulas de histologia, botânica, citologia e zoologia de invertebrados, a Vania atuava no laboratório de Geologia, no qual criou um magnífico acervo de minerais, rochas e fósseis. Além disso, ela definiu uma estratégia de trabalho na disciplina que os professores que a sucederam mantiveram.

Em especial, a principal marca que a Vania deixa nas disciplinas em que atua, em diferentes cursos, são as saídas a campo. Desde o primeiro semestre como professora, foi graças a ela que começamos a fazer as saídas a campo do curso. Fazíamos juntas, mas era a Vania que montava os roteiros, organizava os alunos e conseguia o financiamento para as viagens. Ela tinha o gás para esse trabalho árduo e me convidava para oferecermos aos alunos o máximo de atividades possíveis nessas viagens de estudo, pois estes eram trabalhadores e tinham pouca disponibilidade de sábados para viagens de estudos. Várias dessas saídas a campo envolveram lugares distantes e duraram mais do que um dia saíamos no sábado e retornávamos no domingo. Nesses casos os alunos sempre estavam dispostos a sair à noite para jantar e conhecer as cidades, mesmo quando reclamavam muito do cansaço durante as atividades práticas. Nos jantares e passeios, quem os acompanhava era a Vania, porque eu capotava, exausta, e preferia dormir cedo para aguentar as atividades do dia seguinte. Também durante as viagens mais longas era a Vania que inventava brincadeiras no ônibus para manter a turma animada. Eu me impressionava e ainda me impressiono com a disposição e energia da minha colega.

Há muitas coisas que poderiam ser destacadas aqui, pois a Vania sempre foi uma professora muito participativa e atuante na elaboração e ofertas de cursos, na regionalização da UCS, nas atividades de pesquisa, entre outros. Mas, por se tratar de um artigo e não de um livro, é preciso sintetizar, por isso destaco as suas saídas a campo, pois nelas sempre estavam associados a seriedade das coletas e registros de dados e os momentos de pura alegria e convivência saudável. Ou seja, para mim ela trabalha com a perspectiva de que é possível ser um cientista sem deixar de ser sociável e alegre (Figura 2). Em outras palavras é preciso endurecer sem perder a ternura jamais!

Gladis Franck da Cunha

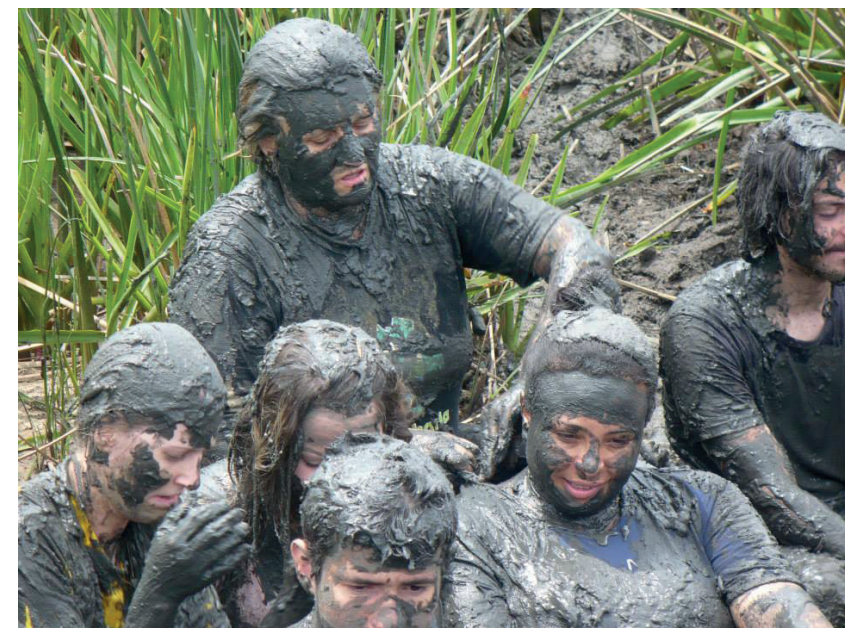

Figura 2: Vania em pé, ao fundo, participando de um banho de lama após uma atividade prática em um manguezal (foto obtida do acervo de seu perfil no Facebook).

\section{A ORIENTADORA, A AMIGA E A COLEGA!}

A vida realmente nos conduz por caminhos estranhos. Era o ano de 2006 quando eu estava para finalizar a minha graduação e tinha que escolher o tema do meu Trabalho de Conclusão de Curso (TCC). A opção foi por aprender sobre gerenciamento de resíduos sólidos, escolha um tanto curiosa para quem não tinha conhecimento sobre o tema. Fui direcionado para ser orientado pela professora Vania devido ao assunto que escolhi. Confesso que eu não a conhecia e nunca havíamos tido nenhum tipo de contato anterior. À medida que tive as primeiras reuniões com ela percebi o quanto eu poderia aprender com base em todo o conhecimento, a experiência profissional e a paciência que a professora Vania tinha para compartilhar o que sabia. O TCC foi o pano de fundo para edificarmos uma amizade sólida que até hoje se renova a cada dia.

Dentre todos os recomeços que a vida nos proporciona, optei por findar um ciclo de trabalho na indústria após a conclusão do curso de Engenharia Química e fui atuar como bolsista graduado em um projeto de pesquisa da UCS. Para a minha grata surpresa, eu havia sido indicado pela própria professora Vania. Mais uma vez nossos caminhos estavam se cruzando. Nesse período nos tornamos mais próximos, já que ela era parte integrante da equipe do projeto. Aprendemos, discutimos, rimos e brigamos. Sim, brigamos, pois nem sempre a troca de ideias é algo que fazemos de forma passiva. Foi um período excepcional, o recém-graduado se tornou um mestrando e o mestrando se tornou um doutorando. E as conversas na sala da professora Vania sobre o projeto, a engenharia, o meio ambiente e a vida se intensificaram ao ponto de eu ter me tornado "alguém da casa"! Um indício de que a mentora tinha se tornado minha amiga das horas certas e incertas!

Comecei essas linhas dizendo que a vida nos conduz por caminhos estranhos. E quão estranhos foram esses caminhos! 


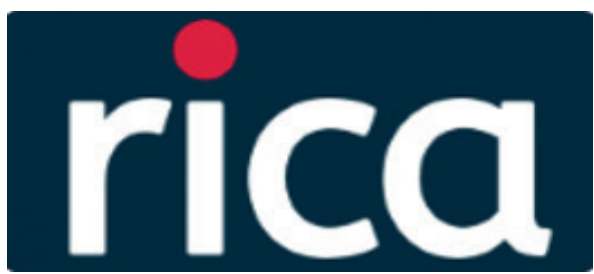

Depois de um tempo curto afastado do Laboratório de Polímeros da UCS, com o término do meu doutorado eu estava em uma saída a campo com o pessoal do Instituto de Saneamento Ambiental da UCS quando recebi um telefonema sobre a abertura de um edital para seleção de professores na UCS. O início da minha carreira como professor não veio nesse edital, mas no processo seletivo seguinte. Novamente a professora Vania teve um papel de destaque auxiliando um professor iniciante na docência e na pesquisa. Nossa amizade foi renovada mais uma vez e a mentora e amiga se tornou minha colega!

Esse breve relato, de uma amizade de mais de 15 anos, demonstra o quanto a professora Vania influenciou e ainda vai influenciar positivamente o crescimento pessoal e profissional de tantos outros estudantes. Agradeço muito por fazer parte dessa história tão vencedora e motivadora que é a alquimia de transformação que a professora Vania fez e continua fazendo na vida de tantas pessoas! Gratidão!

\section{Matheus Poletto}

\section{UMA PROFESSORA, PESQUISADORA E AMI- GA PARA LÁ DE ATIVA}

Aproximei-me da Vania em 2008, no Active Learning in Engineering Education (ALE) em Bogotá, Colômbia. Eu estava na UCS desde 2003 e vinha participando desses eventos internacionais de aprendizagem desde 2005, então, como estava muito entusiasmada com a qualidade deles, fiz uma divulgação intensa na UCS, convidando os colegas da área a participarem contando suas experiências. A Vania, uma professora mediadora e educadora no sentido mais amplo da palavra, que realmente concebe e desenvolve ambientes de aprendizagem ativa como poucos, resolveu enviar uma contribuição para o congresso. Nunca tínhamos interagido, mas, de repente, descobrimo-nos e passamos quatro dias conversando, tanto que quase faltou água em Bogotá para renovar nossas salivas. Tivemos pouco tempo para conhecer Bogotá como turistas (Figura 3), mas em todos os lugares que passamos a Vania sempre apresentou aquele olhar curioso de bióloga e cientista. Quando ela não estava avaliando a questão dos resíduos, estava apontando a riqueza da flora local.
RICA - v. 5 n. 9, 2021

Revista Interdisciplinar de Ciência Aplicada

ISSN: 2525-3824

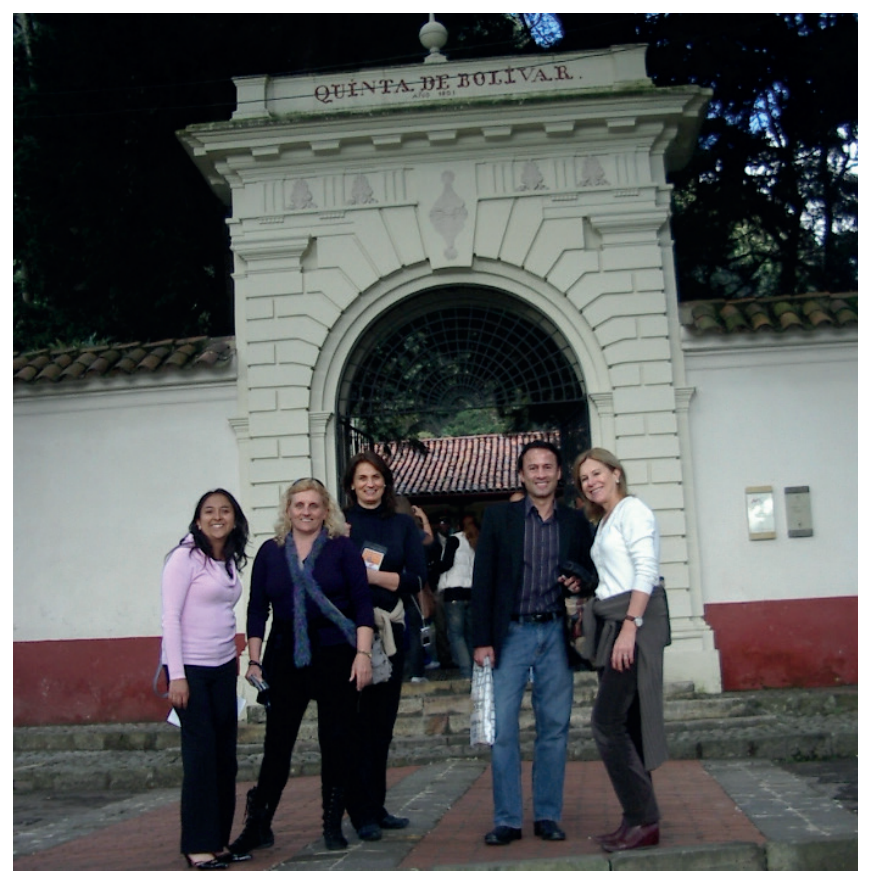

Figura 3: Vania, colegas da UCS (Professoras Isolda Gianni de Lima e Laurete Sauer) e colegas da Universidade de Los Andes em Bogotá (acervo pessoal de Valquíria Villas-Boas)

Terminado o evento e de volta a Caxias do Sul, adaptamos uma oficina sobre Trabalho em Equipe da qual participamos no ALE 2008 e a oferecemos, junto às Professoras Laurete Zanol Sauer e Isolda Gianni de Lima, na Semana Acadêmica do então Centro de Ciências Exatas e Tecnologia (CCET) da UCS. Envolvemos também outros professores do CCET e posso garantir que a oficina foi um sucesso entre os estudantes da Licenciatura em Matemática e das Engenharias.

Em 2011 voltamos a participar de um Active Learning in Engineering Education Workshop (ALE), dessa vez em Santiago, Chile, e mais uma vez apresentamos nossos trabalhos, aprendemos muito e por todo lugar que passava a Vania ia fotografando resíduos, lixeiras e caminhões de lixo. Quando o assunto não era lixo (Figura 4), era água (Figura 5), e ela sempre nos esclarecia os pontos positivos e negativos do sistema de coleta e outros fatores, ou seja, tínhamos passeios turísticos muito instrutivos, verdadeiras aulas com experimentos de demonstração. 

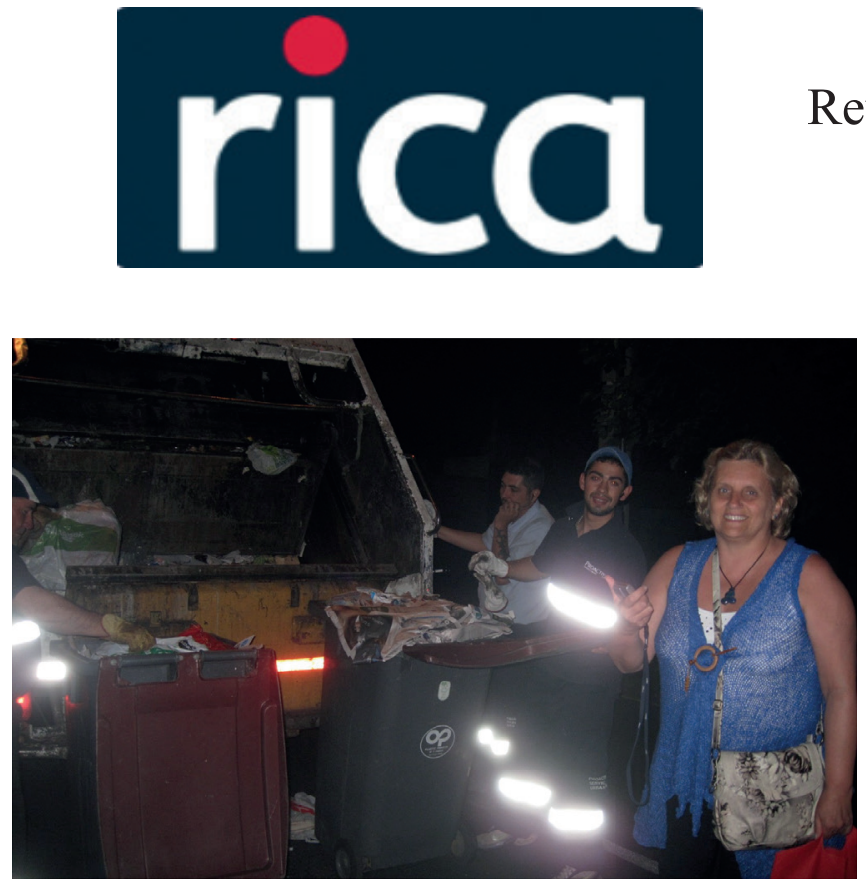

Figura 4: Vania conversando com os catadores chilenos (acervo pessoal de Valquíria Villas-Boas)

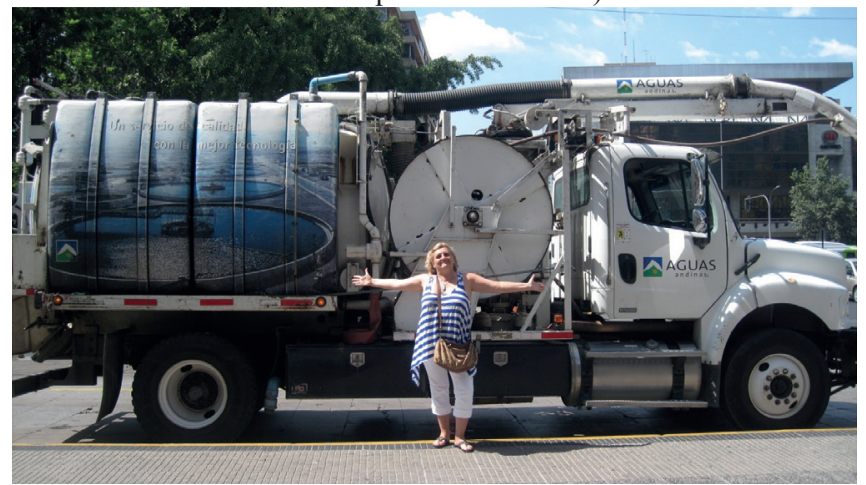

Figura 5 - Vania em frente a um caminhão da agência de águas chilena (acervo pessoal de Valquíria Villas-Boas)

Em 2013, capitaneados pelo professor Francisco Catelli, Vania, Isolda, Laurete, Gladis, eu e mais alguns colegas (Odilon Giovannini, Ivete Booth, Ana Grisa, Alexandre Mesquita, Carine Webber, Marilda Spindola) iniciamos o Programa de Mestrado em Ensino de Ciências e Matemática da UCS, no qual Vania e eu orientamos estudantes e mantemos a parceria em disciplinas. De uma das orientações, um trabalho foi produzido e apresentado no ALE 2015 em San Sebastian, Espanha (Figura 6).

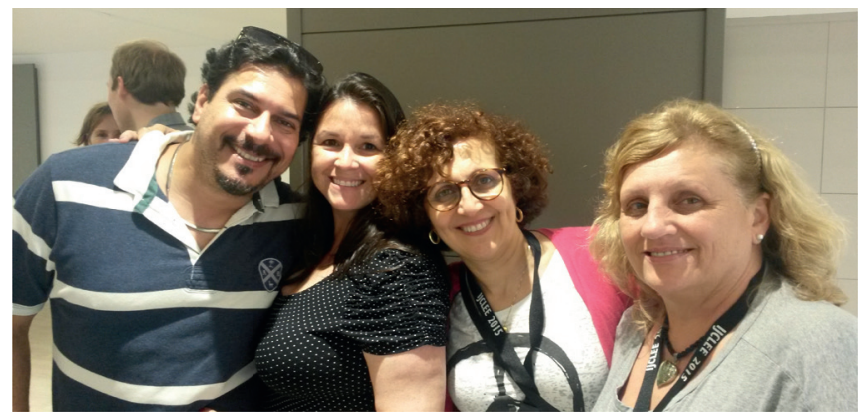

Figura 6: Vania, eu e colegas no ALE 2015 (acervo pessoal de Valquíria VillasBoas)

Uma coisa é certa: ir a um congresso com a Vania é sempre uma aventura científica, turística e de momentos para fortalecer a
RICA - v. 5 n. 9, 2021

Revista Interdisciplinar de Ciência Aplicada

ISSN: 2525-3824 amizade. Uma das coisas mais difíceis nessas ocasiões é deixar o corpo descansar quando se tem tanto a ver e compartilhar.

Eu poderia usar muitas e muitas mais páginas para falar da minha parceria e amizade com a Vania, poderia falar muito mais sobre a Vania professora para a qual um ambiente de aprendizagem ativa é a aula dela de todas as semanas - mas exemplos desses ambientes já foram mencionados -, poderia falar da Vania pesquisadora e diretora do Instituto de Saneamento Ambiental - ISAM, que tem formado muitos cientistas na área ambiental, que aprova muitos projetos das agências de fomento, que escreve e publica muitos artigos e tem organizado muitos eventos científicos importantes; contudo, vou terminar minha contribuição a esta homenagem dizendo o quanto sou grata por tê-la como colega de trabalho, colaboradora e amiga. Ela é uma pessoa que espalha uma energia gigante por onde passa com seu sorriso e seus abraços verdadeiros. Viva a Vania!

Valquíria Villas-Boas

\section{PROFESSORA VANIA OU VANIA???}

Em momentos formais é professora Vania, mas o tempo de convivência me permite chamá-la somente de Vania.

São tantas vivências, trabalhos, saídas a campo e aulas práticas até a orientação do mestrado que tenho certeza de que nos conhecemos há muito mais que 25 anos. Aprendi com a professora Vania que podemos tudo o que queremos, basta ter fé, vontade e acreditar em si mesmo. E o mais importante: ter confiança nas pessoas que trabalham conosco e gostar do que fazemos. Aprendi com a Vania a ter paixão pela minha formação e profissão. Ela sempre esteve ao meu lado nas ocasiões mais importantes. Sou muito grata por ter você na minha vida, tanto pessoal quanto profissional. Espero que eu ainda possa desfrutar de sua companhia e seus ensinamentos por muito tempo!

Fernanda Marcon Angheben

\section{COMO SEPARAR O EDUCADOR, O PROFISSIONAL E O SER HUMANO?}

Isso é fácil quando:

- o educador acredita que é possível ensinar apenas conteúdos como verdades;

- o profissional acredita que estas são dimensões separadas e excludentes;

- o ser humano ilusoriamente crê que podemos ser o que queremos em cada espaço que ocupamos na vida.

Mas é impossível quando:

- o educador tem a exata dimensão da sua importância na construção de profissionais cidadãos que sabem colocar o coletivo acima do interesse individual; 


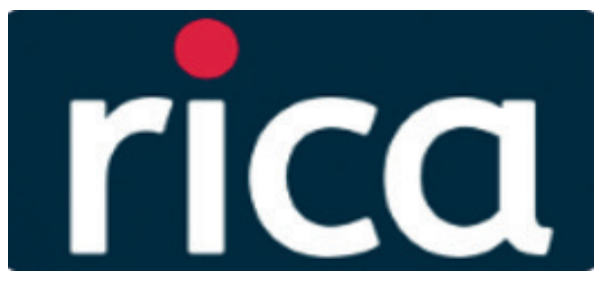

- o profissional percebe que a socialização e a construção de conhecimentos são atribuições inerentes ao bom profissional;

- o ser humano é tão vibrante que tudo o que faz se integra, produzindo algo que é bem maior que a simples soma de partes.

Assim é e sempre foi nossa homenageada. Vania é aquela educadora que forma em qualquer espaço (seja na sala de aula, nas saídas a campo, nos laboratórios ou no ISAM); é uma pessoa vibrante que coloca tanta energia no que faz que, às vezes, explode em emoções poderosas a ponto de abalar estruturas; é a bióloga apaixonada que insiste em querer salvar o planeta e nos impõe (de modo amável e convincente) um amor e uma responsabilidade pela qualidade ambiental e de vida.

Estar dividindo espaços com ela sempre foi um privilégio. Testemunhar seus avanços pessoais e científicos e suas lutas, uma lição de vida. Perceber e estar em seus momentos de fraqueza, uma oportunidade de consolidar a amizade.

Espero que Vania prossiga pintando a vida bem colorida com a sabedoria de quem escolhe as cores certas para cada momento e que as use com a inteligência que lhe é inerente, mantendo esse olhar de fé e de esperança.

\section{CODA}

Nilva Lúcia Rech Stedile

Certos poemas, músicas ou canções parecem terem sido compostos para algumas pessoas, mesmo que em um tempo diferente. Como traduzir a Vania em versos, com sua enorme energia, generosidade, superesforços, luta incansável e produção de conhecimento e de vida? Pensamos no mar! Assim, todos os recortes pessoais e emocionais nos evocaram versos de Fernando Pessoa [2]:

\section{MAR PORTUGUÊS}

Ó mar salgado, quanto do teu sal São lágrimas de Portugal!

Por te cruzarmos, quantas mães choraram, Quantos filhos em vão rezaram!

Quantas noivas ficaram por casar

Para que fosses nosso, ó mar!

Valeu a pena? Tudo vale a pena

Se a alma não é pequena.

Quem quer passar além do Bojador

Tem que passar além da dor.

Deus ao mar o perigo e o abismo deu,

Mas nele é que espelhou o céu.
RICA - v. 5 n. 9, 2021

Revista Interdisciplinar de Ciência Aplicada

ISSN: 2525-3824

\section{REFERÊNCIAS}

[1] SCHNEIDER, V. E. Currículo do sistema currículo Lattes. [2021]. Disponível em: http://lattes.cnpq.br/9940289333509769. Acesso em: 31 mar. 2021.

[2] PESSOA, F. Mar português. Arquivo Pessoa. Disponível em: http://arquivopessoa.net/textos/2405. Acesso em: 06 maio 2021. 